\title{
WHY SIMULATE A SAMPLE OF RECYCLED WOOD?
}

\author{
A. Bouslamti ${ }^{\wedge}$, M.A. Irle ${ }^{1}$, C. Belloncle ${ }^{1}$, V. Salvador ${ }^{2}$, M. Bondu ${ }^{2}$, S. Hulot ${ }^{2}$, B. Caron $^{2}$
}

\begin{abstract}
Wood products follow the same cycle as other materials: manufacture, use and disposal. For certain applications, chemical additives are added to wood to increase its durability against biological and physical attack. At the end of life, waste wood is chipped or crushed before being recovered as raw material for new products or as fuel for energy. In recycled wood, there is the potential that some wood particles are contaminated by hazardous substances, such as organic or heavy metal preservatives. Therefore there is a need for a quality control method of assessing recovered wood that is on the one hand sufficiently precise and on the other not too expensive to preclude the use of recycling wood in to new products.

This paper covers some preliminary research that is part of a large study that aims to develop a robust analytical method for recovered wood. However the extreme variability of recovered wood makes it difficult to develop such protocols on real recovered wood samples. Consequently, model chip piles with known contamination levels were created to simulate real world recovered wood samples.
\end{abstract}

Keywords: Recovered wood, particle size, sample size, heavy metals, AAS and ICP-AES.

\section{INTRODUCTION}

The world annual production of wood preservatives is estimated to be about 500,000 tonnes per year (Helsen and Van den Bulck 2005). This is used to treat around 30 million $\mathrm{m}^{3}$ of wood a year. It is thought that $66 \%$ of this volume is treated with copper chromium arsenate (CCA) (Humphrey 2002, Jacobi et al. 2007). Eventually this wood will reach the end of its useful life and will have to be disposed of.

In France, recovered wood is classified in to three categories according to the level of hazardous substances it contains: clean wood (Class A); wood treated with non-hazardous products (Class B), e.g. paints, varnishes, etc. and wood treated by impregnation with hazardous products (Class $\mathrm{C}$ ), e.g. CCA, CCB, etc. It is estimated that 16 million tonnes of recovered wood is generated each year in France alone (CTBA 2003, Galos 2005). Of this 83\% originates from packaging and so is of class A, leaving $17 \%$ being a mixture of class B and C from construction and demolition (CEBTP 1999, Daniel et al. 2007).

Class C materials often contain high levels of heavy metals and cannot therefore be recycled to make other products. Various cleaning systems have been proposed (Oskoui 2004, Clausen and Kenealy 2004), but such proposals tend to focus on the recovery of the heavy metals in order to reuse

\footnotetext{
${ }^{1}$ PRES UNAM, Laboratoire Matériaux Composites Bois, Ecole Supérieure du Bois rue Christian Pauc, BP10605, 44306 Nantes, France. ${ }^{2}$ IDAC Route de Gachet BP 52703, 44327 NANTES Cedex 3, France.

Corresponding author: ^Amine.BOUSLAMTI@ecoledubois.fr

Received: 05.04.2011 Accepted: 30.01.2012
} 
them or make them safe and the wood is destroyed in the process. Class B materials on the other hand, should not contain high concentrations of heavy metals and can be reused in two ways.

The first is by recycling in to new wood products, for example particleboard manufacture (Wang et al. 2008) the production of which currently consumes 2.4 million tonnes of clean virgin wood in France (Mille et al. 2005). The second way is to burn the wood for energy production (Paulrud et al. 2002). Concern is increasing about tracing the origin of recovered wood for domestic energy purposes because of potential toxic emissions during combustion operation (Allemand 2003).

As mentioned above, Class C materials are classified as hazardous substances and so cannot be recycled, but, Class B can be used even though it contains some heavy metals (as does clean wood for that matter). It is surprising that there are no pan-European regulations that designate the maximum permissible concentrations of heavy metals in recovered wood. Only Germany has specific regulations (GFG 2002) that define the uses of recovered wood. The largest user of recovered wood in Europe is the particleboard industry (European Panel Federation (EPF) 2010). Consequently, the EPF has defined its own regulations (EPF 2001) that all its members adhere to. The limits contained in the EPF standard are derived from a European regulation on the materials used to manufacture children's toys that may be placed in the mouth (EN 71-31995). The limits are given in table 1.

Table 1: The maximum allowable quantities of contaminants permitted in particleboard manufactured to EPF's Industry Standard (EPF, 2002).

\begin{tabular}{|l|l|l|l|}
\hline Contaminant & Limit $(\mathbf{p p m})$ & Contaminant & Limit $(\mathbf{p p m})$ \\
\hline Arsenic $(\mathrm{As})$ & 25 & Lead $(\mathrm{Pb})$ & 90 \\
\hline Cadmium $(\mathrm{Cd})$ & 50 & Mercury $(\mathrm{Hg})$ & 25 \\
\hline Chromium $(\mathrm{Cr})$ & 25 & Fluorine $(\mathrm{F})$ & 100 \\
\hline Copper $(\mathrm{Cu})$ & 40 & Chlorine $(\mathrm{Cl})$ & 1000 \\
\hline Pentachlorophenol $(\mathrm{PCP})$ & 5 & Creosote & 0,5 \\
\hline
\end{tabular}

The heterogeneous character of recovered wood, e.g. origin of waste wood, particle size and degree of contamination, etc., make it difficult to make a qualitative analysis of suitability of the wood for recycling and a precise quantitative analysis of chemical contamination is practically impossible and rarely attempted. The development of an analytical method that is sufficiently accurate and not excessively costly is required to ensure the continued use of recovered wood in a responsible manner.

This paper describes some research that is part of a programme that aims to develop a robust protocol for the evaluation of contamination levels in recovered wood. The difficulty with this research is that using real world samples of recovered wood poses the problem of how to determine the contamination level without destroying the sample. Consequently, an alternative approach is taken here in that a sample of recovered wood is simulated by using clean wood that is contaminated with known concentrations of various metals.

The laboratory treated wood will be used to investigate the effect of different sampling and subsampling techniques on the contamination levels observed in subsequent analyses.

\section{MATERIALS AND METHODS}

Approximately, $50 \mathrm{~kg}$ of chips were obtained commercially. Two samples of recovered wood and one of clean wood. The latter particles were dried at $65^{\circ} \mathrm{C}$ for 72 hours to achieve a moisture content 
of approximately $5 \%$. The samples were then sieved using a Retsch AS 200 (3D) sieving machine with decreasing screen sizes $(8,2.8,2.5,2,1,0.5$ and $0.1 \mathrm{~mm})$.

The following three different methods of digesting wood samples were used during this research:

- Microwave digestion: $1 \mathrm{~g}$ of wood flour is placed in the digestion tube with $4.5 \mathrm{ml}$ of $\mathrm{HNO}_{3}$ (65\%) and $0.75 \mathrm{ml}$ of $\mathrm{H}_{2} \mathrm{O}_{2}(50 \%)$. Then the digestion tube is placed vertically in the microwave system (MLS-1200 MEGA). The power of the microwave oven should be fixed at $1500 \mathrm{~W}$ for 10 minutes. After cooling the digestion solution is diluted with distilled water in a $100 \mathrm{ml}$ flask.

- Hot block digestion: $0.5 \mathrm{~g}$ of wood flour, $4 \mathrm{ml}$ of $\mathrm{HCl}(37 \%)$ and $2 \mathrm{ml}$ of $\mathrm{HNO}_{3}(65 \%)$ are heated from room temperature to $120^{\circ} \mathrm{C}$ within 2 hours and maintained for 2 hours. After digestion, $5 \mathrm{ml}$ of the solution is taken and made up to $50 \mathrm{ml}$ with distilled water.

- Digestion by wood calcination: $2 \mathrm{~g}$ of wood flour is collected and placed in a crucible with $2 \mathrm{ml}$ of $\mathrm{H}_{2} \mathrm{SO}_{4}(70 \%)$. Then the crucible of calcination is placed in an oven system (Nabertherm Controller P320). The wood sample is calcined at $700{ }^{\circ} \mathrm{C}$ for 15 minutes. After cooling the sample is diluted with nitric acid $\left(\mathrm{HNO}_{3}\right.$ at $\left.10 \%\right)$ in $100 \mathrm{ml}$ flask.

Analysis of the solubilised heavy metals was achieved using Atomic Absorption Spectroscopy (AAS-Varian) and Induction Coupled Plasma- Atomic Emission Spectroscopy (Thermo ICAP 6000 series). AAS was used in the analysis of the liquid from recovered wood, whereas ICP-AES was used to analyse solutions from clean wood and from particles impregnated with different strength salt solutions.

All the chemicals used were of analytical grade. Calibration solutions of the different metals salts (boron, copper, chromium and cadmium) from SIGMA-ALDRICH were prepared in order to validate the ICP measurements. The impregnation solution was prepared by dissolving inorganic salts in deionised water (Millipore direct-Q 3UV) as listed in table 2.

A reference material was also used (BCR/NCS DC73349 “Bush Branches and Leaves").

Table 2: Details of the impregnation solutions.

\begin{tabular}{|l|c|c|c|c|}
\hline Metals & boron & copper & chromium & cadmium \\
\hline Metal salts & $\mathrm{B}_{4} \mathrm{Na}_{2} \mathrm{O}_{7}, 10 \mathrm{H}_{2} \mathrm{O}$ & $\mathrm{CuSO}_{4}, 5 \mathrm{H}_{2} \mathrm{O}$ & $\mathrm{KCr}\left(\mathrm{SO}_{4}\right)_{2}, 12 \mathrm{H}_{2} \mathrm{O}$ & $3 \mathrm{CdO}_{4} \mathrm{~S}, 8 \mathrm{H}_{2} \mathrm{O}$ \\
\hline Concentration $(\mathrm{ppm})$ & 3002 & 3001 & 3002 & 3002 \\
\hline
\end{tabular}

\section{RESULTS AND DISCUSSION}

The first task was to check the influence of several parameters on analytical results.

The influence of the wood flour digestion methods on observed heavy metal concentration was therefore investigated (Table 3). The three digestion methods give rather different mean values and coefficients of variation. Given that the same analytical technique was used to analyse all of the solutions, any changes in observed metal concentration must be due to sampling and the digestion technique. The oven method seems to be quite precise because of its low CV, but, the low mean value indicates some loss of metals perhaps through vaporisation. The Hot Block digestion was therefore chosen as the preferred digestion method because it provided the highest metal levels, which is 
important because metal can only be lost and not generated by a protocol. It also gave reasonable $\mathrm{CV}$ values.

Table 3: The influence of digestion method on observed copper levels.

\begin{tabular}{lccc}
\hline Digestion method & Microwave & Oven calcination & Hot block \\
Mass $(\mathrm{g})$ & 0.5 & 1 & 2 \\
No. of analyses & 10 & 6 & 7 \\
Average (ppm) & 12.26 & 9.13 & 12.77 \\
S.D. & 1.20 & 0.46 & 1.46 \\
Variation (\%) & 9.81 & 5.09 & 11.41 \\
\hline
\end{tabular}

In order to check the accuracy of the measurements, a double verification of the analyses was done:

1. A certified reference material (BCR) was tested along side the wood flours used in each set of analyses. All the results obtained from the BCR samples matched those expected for copper and boron, but not all of those for chromium (Table 4).

2. The internally used method of digestion using Hot Block system was compared to that proposed by the American Wood Protection Association Norm (AWPA A7-04/2010), which uses a mixture of nitric, sulphuric or perchloric acids, in digestion tubes at $120^{\circ} \mathrm{C}$ to $150{ }^{\circ} \mathrm{C}$.

Table 4: Comparison between certified values and the obtained values through the preferred digestion method for BCR/NCS DC73349 analysis

\begin{tabular}{|c|c|c|}
\hline BCR & Certified values & Obtained values \\
\hline Copper & $6.6 \pm 0.8$ & $6.9 \pm 1.1(\mathrm{n}=4)$ \\
\hline Boron & $38 \pm 60$ & $36.3 \pm 6.6(\mathrm{n}=4)$ \\
\hline Chromium & $2.6 \pm 0.2$ & $1.5 \pm 0.2(\mathrm{n}=4)$ \\
\hline
\end{tabular}

Figure 1 shows a good linearity between results obtained fromthe two methods. The coefficients of each correlation are significant, thus indicating that the digestion method used for this work provides accurate results for the concentration of boron, copper and chromium in wood samples.

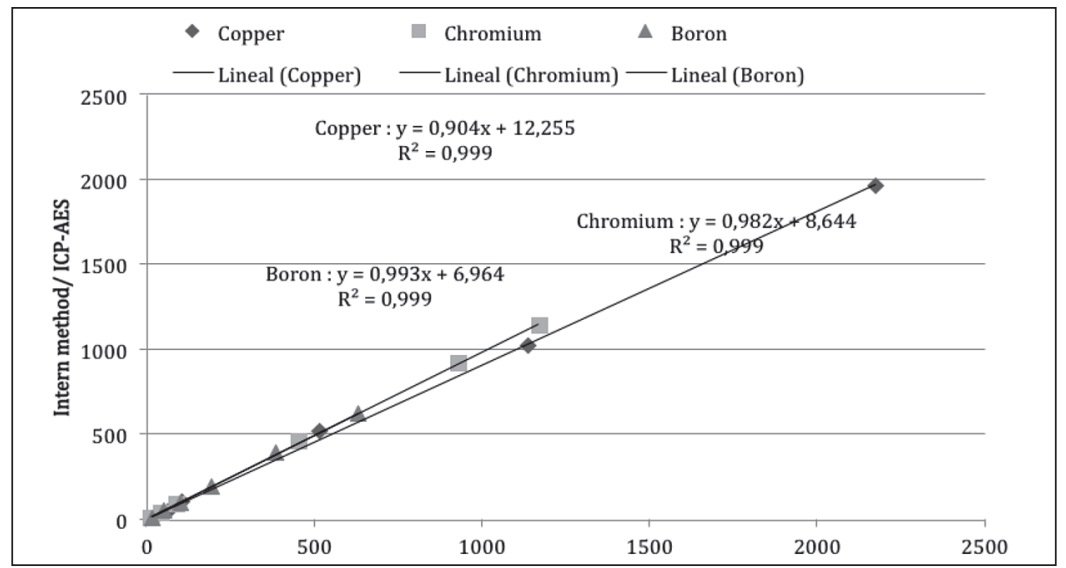

Figure 1: The correlation between AWPA digestion and hot block digestion methods applied on wood treated with boron, copper and chromium. 
The problem of working directly with recovered wood samples taken from industry is clearly shown in table 5 in that the variation in the results is considerable. This may be due to density variation, penetration variation and presence of heartwood-sapwood with different chemical retention values. This has two effects. The first is a low confidence in the mean value which increases the chance of reaching false conclusions from statistical analyses. The second is that in reality, very few replicate samples would be tested by industry and so chance could cause the tester to observe that the stock pile is either very contaminated or only slightly contaminated. One would hope that since this particular stock pile was analysed 29 times that the mean values in table 5 approximate the real mean contamination levels. The levels found are below the permissible levels set by EPF (European Panel Federation).

Table 5: The concentration of three heavy metals found in a sample of "mixed" recovered wood intended for particleboard manufacture in the UK.

\begin{tabular}{|c|c|c|c|}
\hline & Lead & Chromium & Copper \\
\hline Average (ppm) & 52.8 & 16.2 & 13.4 \\
S.D & 100.9 & 19.0 & 12.2 \\
Variation (\%) & 191 & 117 & 91 \\
No. of analyses & 29 & 29 & 29 \\
\hline
\end{tabular}

The samples were taken from the pile following the standard method (NF EN 14778-1 2011). This creates a sample of several kilograms, depending on the size of the particles and estimated weight of the stock pile. The wood must be ground to a fine flour so that it can be completely digested. It was not practical to grind the entire sample to fine flour. Therefore, a sub-sample of wood was actually used for analysis. The wide variations in results of table 5 could therefore be caused by:

1. A non-uniform distribution of chemicals in the stock pile,

2. Bias that is introduced during the sub-sampling of the original sample, or

3. Heterogeneous contamination in the fine flour

The results described above on flour particle size would imply that the last factor would have minimal influence because the flour was ground to smaller than $500 \mu \mathrm{m}$. The influence of the first two factors, however, is not known and this is the reason for creating laboratory treated samples that have known contamination levels.

The first step was to determine the particle size distribution in a typical real-life sample of recovered wood. This is shown in figure 2 . Clean wood chips were then sieved in to the same fractions. These fractions were then impregnated with different metals as described in the methods. The largest fraction was impregnated with boron, the smallest with cadmium and the intermediates with copper and chromium as shown in figure 2. 


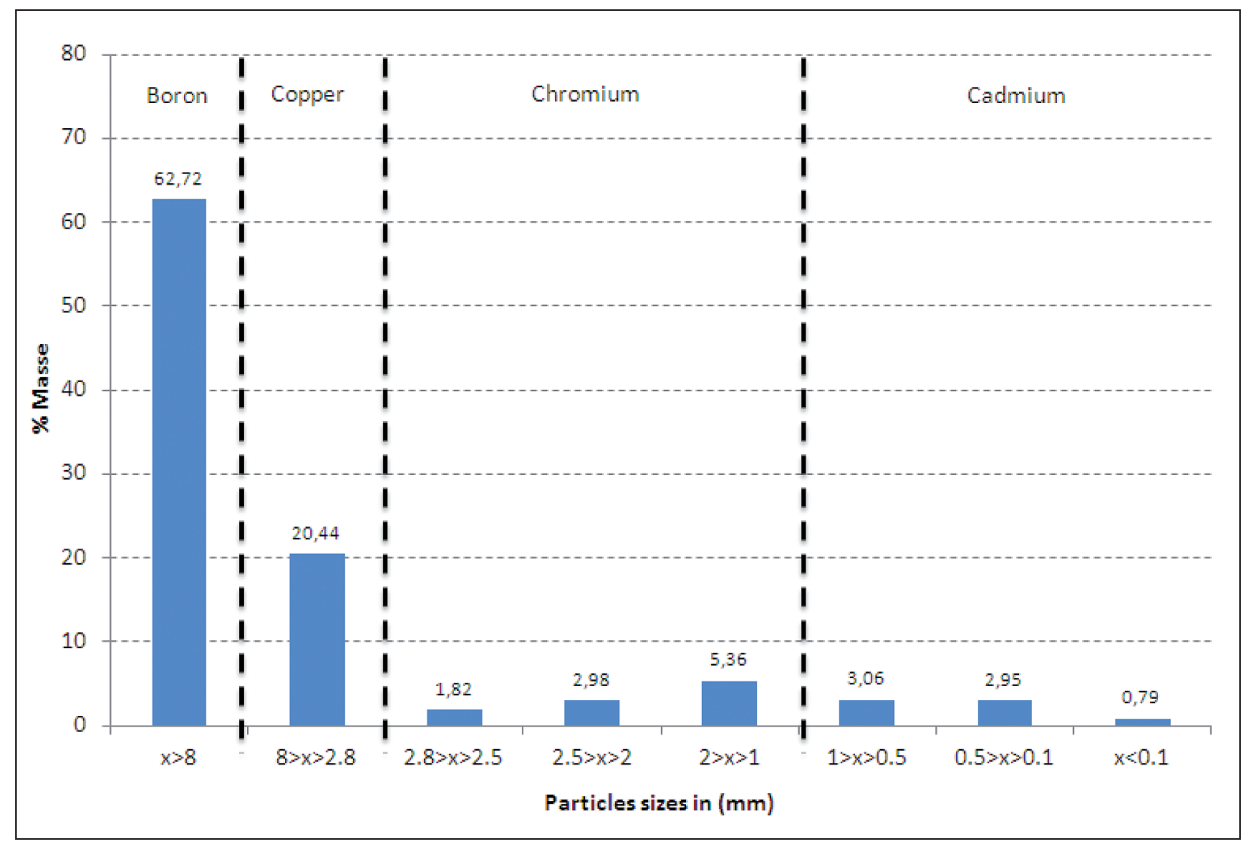

Figure 2: The range of particle sizes and relative proportions found by sieving $10 \mathrm{~kg}$ ofrecovered wood sample obtained from a wood recycling company.

The impregnated chips were mixed with clean wood chips to create wood piles with known particle size distributions and contamination levels. Before this can be done with confidence, the uniformity of the impregnation and concentration of metals in the impregnated chips must be determined.

The fractions were ground separately to a fine flour and then analysed for metal content. The results are given in table 6 . The separate results were analysed with the Dixon test to determine if any of the results contained outlier values. None were found.

Table 6: Analytical results of metal contents in the impregnated fractions.

\begin{tabular}{|l|c|c|c|c|}
\hline & Boron & Copper & Chromium & Cadmium \\
\hline Average $(\mathrm{ppm})$ & 673 & 1955 & 1194 & 7484 \\
\hline S.D. & 65.8 & 124 & 111 & 512 \\
\hline Variation (\%) & 9.8 & 6.3 & 9.3 & 6.8 \\
\hline No. of analyses & 14 & 14 & 14 & 14 \\
\hline
\end{tabular}

The normality of the distribution of results was then analysed with Henry's test (Figure 3) In this test, a straight line indicates normality. The Shapiro-Wilk test was then used to validate this methodology and it confirmed that the distribution of observed concentrations was normal. 


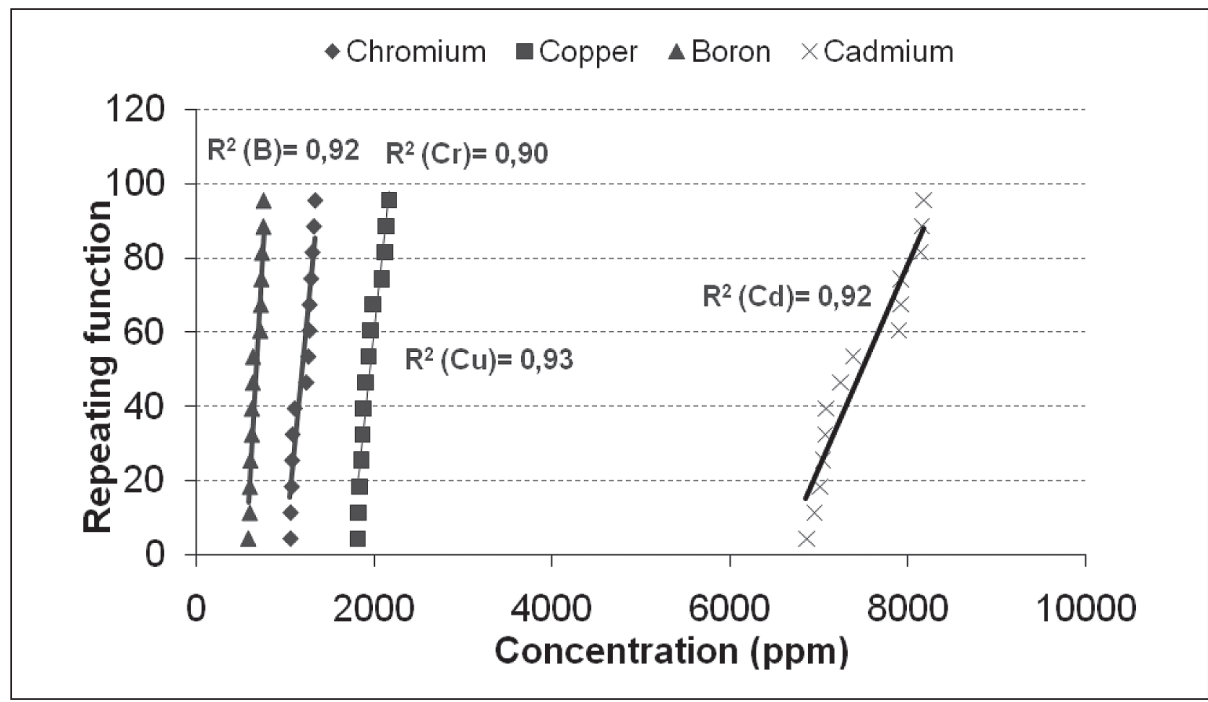

Figure 3: Henry's test applied to the metal concentrations found in the impregnated samples.

\section{CONCLUSION}

The inherent variability of contaminant concentration in recovered wood requires a robust analytical protocol to help ensure that the results are as precise as possible. Although standards exist for taking a sample from a stock pile there are no clear guidelines on how to obtain a representative sub-sample from the main sample, which is often too large to grind to the fine flour needed for chemical analyses. Whilst well used sub-sampling techniques like coning and quartering exist, there is no proof that these methods do not introduce bias when applied to recovered wood samples.

This paper shows how to create model recovered wood piles by using clean wood chips mixed with wood chips that have been previously impregnated with metals. The different chemical and statistical analyses applied to the impregnated wood chips indicate that they are sufficiently uniformly treated.

The suitability of various sub-sampling techniques can then be determined using these model piles. The advantage of using four different metals is that they act as markers for the different fractions, so that when any sample is ground to flour the ratio between the different metal markers will indicate the relative proportion of the different fractions.

Subsequent papers will discuss the effects of different sub-sampling techniques when they are applied to recovered wood samples.

Although this project is using heavy metals as markers, it was considered that the assumptions made on the distributions of heavy metals was just as appropriate for other contaminants, e.g. organic preservatives, paints, plastic coatings, etc.

\section{ACKNOWLEDGEMENT}

The authors gratefully acknowledge the support of the companies PIVETEAU, Bois $2 \mathrm{R}$ and PALEOSS for the wood samples. 


\section{REFERENCES}

Allemand, N. 2003. Estimation des émissions de polluants liées à la combustion du bois en France, Centre Interprofessionnel Technique d'Etudes de la Pollution Atmosphérique (CITEPA). 40p.

AWPA, American Wood Protection Association Standard. 2010. Standard for wet ashing procedures for preparing wood for chemical analysis, A7-04.2.

CEBTP. Centre Expérimental de recherches et d'études du Bâtiment et des Travaux Publics. 1999. C\&D waste, French amount assessment. Fédération Française du Bâtiment (FFB)/ Agence de l'Environnement et de la Maîtrise de l'Energie (ADEME). France, Sophia-Antipolis. 19p.

Clausen, C.A.; Kenealy, W. 2004. Scaled-up remediation of CCA-treated wood. Proceedings of Environmental Impacts of Preservative-Treated Wood.USA, Orlando, Florida. 10p.

CTBA. Centre Technique du Bois et de l'Ameublement. 2003. Guide de gestion des déchets de bois et assimilés en France. CTBA, France, Bordeaux. 117.

Daniel, M. A.; Humar, M.; Okstad, T.; Picardo, V.; Ribeiro, A.; Steierer, F. 2007. Amounts of recovered wood in Cost E31 contries and Europe.Klagenfurt, Austria. $3^{\text {rd }}$ European COST E31 Conference, Management of recovered wood, Autriche, Klagenfurt. pp. 79-116.

EPF. European Panel Federation. 2001. The use of recycled wood for wood-based panels. European Panels Federation Position Paper. EPF, Belgium, Brussels.

EPF. European Panel Federation. 2010. Regional composition of the raw wood consumption mixes in the European particleboard industry. EPF, Belgium, Brussels.

Galos, C.T. 2005. Management of recovered wood: Strategies towards a Higher Technical, Economical and Environmental Standard in Europe. Proceedings of $2^{\text {nd }}$ European COST E31 Conference. Bordeaux. France. 59p.

GFG. German Federal Government. 2002. Ordinance on the Management of Waste Wood. GFG, Berlin, Germany, 31p.

Helsen, L.; Van den Bulck, E. 2005. Review of disposal technologies for chromate copper arsenate (CCA) treated wood waste, with detailed analyses of thermochemical conversion processes. Environmental Pollution 134(2): 301-314.

Humphrey, D.G. 2002. The chemistry of chromate copper arsenate wood preservatives. Inorganic Chemistry 22(1): 1-40.

Jacobi, G.; Solo-Gabriele, H.; Townsend, T.; Dubey, B. 2007. Evaluation of methods for sorting CCA-treated wood. Waste Management 27: 1617-1625.

Mille, B. ; Louvel, V.; Guillo, Y.2005. Guide de gestion des déchets de bois et assimilés en France : la problématique, le gisement, les valorisations, Centre Technique du Bois et de l'Ameublement (CTBA).

Norme Française European Norm. 2011. Biocombustibles- Echantillonnage. NF EN 14778. Association française de normalisation (AFNOR), France, La Plaine Saint-Denis, 62p. 
Oskoui, K.E. 2004. Recovery and Reuse of the Wood and Chromated Copper Arsenate (CCA) From CCA Trenated Wood - A Technical Paper. Orlando, Florida. Proceedings of Environmental Impacts of Preservative-Treated Wood. USA. 387p.

Paulrud, S.; Mattsso, J. E.; Nilsson, C. 2002. Particle and handing characteristics of wood fuel powder: effect of different mills. Fuel Processing Technology 76(1): 23-39.

Wang, S.Y.; Yang, T.H.; Lin, L.T.; Lin, C.J.; Tsai, M.J. 2008. Fire-retardant-treated lowformaldehyde-emission particleboard made from recycled wood-waste. Bioresource Technology 99(6): 2072-2077. 
